\title{
Geospatial Analysis of Breast Cancer in Alexandria: Application of a Novel Public Health Tool
}

\author{
${ }^{1}$ Gihan I Gewaifel, ${ }^{2}$ Mohamed M Bahnasy, ${ }^{3}$ Ibrahim Kharboush, ${ }^{4}$ Omneya G \\ Elsharkawy
}

${ }^{1}$ Department of Public Health, Faculty of Medicine, ${ }^{2}$ Department of Soil and GIS, Faculty of Agriculture, ${ }^{3}$ High Institute of Public Health, Alexandria University, ${ }^{4}$ Alexandria Regional Centre for women's Health and development, Alexandria

Received: July, 2018 Accepted: September, 2018

\begin{abstract}
Background: Geographic information system is a toolbox that can depict geography of $80 \%$ of health problems (epidemiology and outcome) and geography of healthcare systems (screening, prevention, treatment/care services delivery), that can predict future cases levels and trends and show areas with significant clustering of cases to target with prevention and control. Objective: The objectives of the present study were to portray the geographical distribution of breast cancer cases in Alexandria, identify the breast cancer cluster areas in Alexandria, and to calculate the predicted number of breast cancer cases until year 2020. Method: Breast cancer cases clinically and pathologically diagnosed and confirmed in Alexandria University Hospital, Medical Research Institute and Ayadi Almostakbal in Alexandria, over 10 years, between January 1, 2005 and December 31, 2014 and diagnosed and managed in the three enrolled data warehouse were obtained. A digitalized map of Alexandria was used. The data of breast cancer prevalence was overlaid and spatial analysis of prevalence by district and locality was generated using GIS software. Results: Cancer breast cases through 2005-2014 in Alexandria were 6806 cases of which 4534 cases were geocodable. Four Clusters of districts were found, and the characteristics of each cluster was portrayed and mapped. Projection and prediction of cancer breast revealed 704 cases in Alexandria in year 2020 with a consistent increase in cases. Conclusion: Montaza district was the most significant cluster area.
\end{abstract}

Keywords: cancer breast; spatial analysis; GIS; public health tool

Corresponding author: Dr Gihan Gewaifel Email: ggewaifel@yahoo.com

\section{Introduction}

Public health has been significantly transformed by information technology. No one can doubt that the rapid proliferating computer-driven information systems have changed how we organize healthcare, understand health needs, and deliver services. ${ }^{1,2}$

A significant and important characteristic of health and medical information is the geographic relevance. ${ }^{2,3}$ Geographic information system (GIS), received a global interest in recent years mainly because it links geographic locations with dynamics of the studied disease (e.g., cases, demographics, environmental threats, occupational exposures...etc.), visually displaying spatial associations. ${ }^{4-6}$ There is regional diversity in population density, age, disease occurrence, future growth, environmental risk factors, poverty and the ability to access care. Against this, the distribution of health care providers, clinics and specialized centers also varies substantially across different geographical areas. ${ }^{4,5}$ 
GIS enables the spatial contextualization, (e.g. environmental, physical, demographic, ethnic and social) of health and disease data. ${ }^{5}$ It can show geography of the disease (epidemiology and outcome) and geography of healthcare systems (screening, prevention, and treatment/care services delivery. ${ }^{5,6,11}$

More than $80 \%$ of health data, including that of cancers, have locational characteristics. One of the ways to classify information systems is to divide it into two major types/systems: nonspatial information where data cannot be geographically managed and spatial (geographic) information, where data can be geographically managed. ${ }^{7-9,14,15}$

In Egypt, cancer breast represents $18.9 \%$ of total cancer cases $32.04 \%$ in women and $2.2 \%$ in men) with an age-adjusted rate of 49.6 per 100000 population..$^{12,13}$ In its early treatable stage, cancer breast has a $97 \%$ probability of surviving 5 years. However, woman's likelihood of surviving 5 years decreases to $20 \%$ once it spreads to other body parts. ${ }^{7}$

Cancer incidence and mortality display strong geographic patterns worldwide and in Egypt. The environment where individuals live is increasingly recognized as important across the cancer control continuum, including the risk of cancer development, screening, diagnosis, treatment, and mortality.

The use of spatial epidemiological approaches to identify and characterize cancer clusters can help identify where to make best use of the limited funding available or allocate resources for education, prevention, and treatment in order to have the greatest impact and return on that investment. Moreover, it can help to identify important prognostic factors that are linked to geography and generate hypotheses for further investigation and research into survival disparities.

There was no population based epidemiological evidence to provide spatial distribution of cancer breast in
Alexandria before the present study, especially from a population-based cancer registry provided evidence of increasing breast incidence during the study period. Previously, a small-scale, hospital-based study from Alexandria, Egypt had suggested an increase in incidence rate of cancer breast there ${ }^{16}$ comparing different clusters to each other.

The aim of this study is to assess, explore, and map the spatial distribution of breast cancer cases in Alexandria, Egypt, using Geographic information systems.

This study is also aiming at building-up a digital georeferenced database for breast cancer cases in Alexandria Governorate, Egypt, portraying the geographical distribution of breast cancer cases, identifying the breast cancer cluster areas in Alexandria, determining the relative risk of breast cancer in Alexandria by comparing different clusters to each other and predicting the number of breast cancer cases until year 2050 .

\section{Method}

Target population and sampling: Breast cancer cases clinically and pathologically diagnosed and confirmed in Alexandria Governorate, Egypt. Three data warehouses were included, namely, Alexandria University Hospital oncology department, Medical Research Institute oncology department and Ayadi Almostakbal (a non-governmental oncology centre in Alexandria). Records from ten years between January 1, 2005 and December 31, 2014 were included in the study. A total sample of 7900 cases was included. These are the largest public-sector cancer case banks in Alexandria where they serve four governorates namely Alexandria, El Behera, Kafr El Sheikh and Matrouh.

The study design: A retrospective survey was carried out where the records were reviewed to collect data about the illness and some of the socio-demographic and obstetric factors for all the cases. A 
transfer sheet prepared by the research team including data of the admission form of the three hospitals included. Data were collected through 2005-2014.

Research Setting: For each case, the following information from routinely collected registry data was obtained: age at diagnosis, sex, address (urban/rural, mobile or not), obstetric history and contraception, family history, smoking status, occupation, basis of diagnosis, tumor grade, stage, morphology, tumor behavior, and place of referral.

Urban and rural designations were made according to the Central Agency for Population Mobilization and Statistics (CAPMAS) definitions. Each case in the registry was assigned a residence code based on their residential address that follows the CAPMAS.

The analyses of spatial clustering of cancer have been based on address at the time of diagnosis. An underlying suggestion in these spatial analyses is that residence can be used as a proxy for environmental threats or exposures. However, earlier exposures should be considered too. ${ }^{19-20}$ Statistical analysis was performed using IBM SPSS V20. All statistical tests were two tailed with $\mathrm{P}$ value $<0.05$ to be considered statically significant.

The administrative boundaries for Governorates, districts, and sub-districts (Shyakha) representing Egypt were downloaded from the Central Agency for Public Mobilization and Statistics (CAPMAS). ${ }^{21}$ The maps were in shape file format, and having latitude-longitude coordinate system.

Population data for Alexandria Governorate were obtained from the 2006 census on the 16 districts (Kism, meaning police station) comprising the Governorate. The data included the number of male, female and total population (CAPMAS). Moreover, the percentage of population growth was obtained (Table 1), and numbers of male, female, and total persons were adjusted over the years of study (2005-2014).

Projection of the number of cancer breast cases in the coming years till 2050 was done using the following formula:

Predicted number of cases $=$ Intercept + coefficient $*$ year.

Where the intercept is the constant and the coefficient is beta coefficient which is the estimates resulting from a regressive analysis.

Address Matching: The patients' dataset included the addresses described on the basis of the house number, the name of the street, the district, and the Governorate. Cases where the address was incomplete were discarded from being mapped. Google maps were utilized to locate the addresses of the cases, followed by getting the coordinates of the house in latitudelongitude format, then copied and inserted into the Excel worksheet, to complete the patient record. ${ }^{22}$ Datasets from Excel worksheet were exported to GIS software. The ellipsoid used to map the data was World Grid System 1984 (WGS84).

GIS Analysis: The administrative boundaries were downloaded from the Central Agency for Public Mobilization and Statistics (CAPMAS) ${ }^{21}$ website. The maps were in shapefile format and having latitude-longitude coordinate system, then converted to UTM coordinate system. The location of the Alexandria Governorates and its districts is shown in figure (1).

The GIS analysis included map overlay, table joining, merging, spatial overlay, etc. Commercial GIS analysis software were utilized, along with other opensource software such as SatScan, and GeoDa. ${ }^{19-31}$

Disease prevalence, clustering, relative risk and significance of clusters $\left(\mathrm{Gi}^{*}\right.$ statistic) were among the most important variables to be calculated. These attributes were mapped based on their 


\section{Table (1): Egypt Population Growth (PG\%) over the studied period (CAPMAS)}

\begin{tabular}{|l|l|}
\hline Year & PG $(\boldsymbol{\%})$ \\
\hline 2005 & 1.812442 \\
\hline 2006 & 1.761984 \\
\hline 2007 & 1.730022 \\
\hline 2008 & 1.750948 \\
\hline 2009 & 1.839638 \\
\hline 2010 & 1.967711 \\
\hline 2011 & 2.106638 \\
\hline 2012 & 2.211107 \\
\hline 2013 & 2.254326 \\
\hline 2014 & 2.218863 \\
\hline
\end{tabular}

distribution in different districts in Alexandria Governorate.

The adjusted population per district was used to calculate the prevalence rate for breast cancer in Alexandria Governorate. The obtained patients' data for the period 2005-2014 were overlain with the district boundaries to get the number of cases for each district, which was divided by the number of female per district and multiplied by 100,000 to get the breast cancer period prevalence for that year. The yearly results were mapped separately for the period 2005 - 2014, then, combined for the whole period Clustering was performed on the basis of grouping both the districts and the breast cancer cases found in those districts.

Relative risk was calculated by using the likelihood ratio which was calculated using spatial scan statistics software.

\section{Results}

A total of 7900 breast cancer cases with an average age of $52.2 \pm 11.9$ years were identified. Alexandria contributed to $86.2 \%$ of cases (figure 2). Almost all cases had been diagnosed by pathological confirmation (97.8\%). Most cases were either stage II (37\%) or stage III $(44.6 \%)$ while $4.2 \%$ and $14.2 \%$ of cases were in Stage I and IV respectively. Table 2 portrays the biostatistical analysis of the enrolled cancer breast cases residing in Alexandria as compared to non-Alexandria residents regarding some clinic-epidemiological characteristics.

\section{Results of GIS analysis:}

The data concerned 7900 cases, of which 6806 cases were residents in Alexandria Governorate and 1094 coming from different affiliated governorates. In Alexandria, 4534 cases were geocodable. (Table 3).

Clustering was performed on the basis of grouping the breast cancer cases based on the distance between cases. Four significant Clusters were determined by the spatial scan statistic with the relative risk and $p$ value for each cluster portrayed in table (4) and mapped in Fig (3).

The true clusters are contiguous, whereas false clusters are dis-contiguous.

In order to confirm the significance of the clusters, $\mathrm{Gi}^{*}$ were calculated, and shown in figure (4). It is clear that cluster no. 3 found in Montaza district has the highest significance of all other districts, which confirms the distribution of patients clusters in different districts.

The incidence of Breast Cancer rates in each district was obtained and illustrated in figure (5). It is clear that the highest incidence rate is located in the districts where most of observed cases had breast cancer in relation to the total women population, namely, Al-Atarin, AlMansheyya, and Al-Gumruk.

The relative risk for developing cancer is shown in figure (6). Montazah district has the highest number of breast cancer cases, and considered as a significant cluster.

Regarding projection of cancer breast in Alexandria for the coming years, a multiple linear regression was carried out to calculate the predicted the number of breast cancer cases until year 2020, and the results reveal that the regression coefficient (r2) is 0.69 and standard error equals 60.2 , with the following equation: Predicted No. of cases $=-58517+(29.32$

$$
* \text { year } \pm 60.2 \quad \mathrm{r} 2=0.69 "
$$


Table (2): Distribution of the personal characteristics of enrolled breast cancer cases by their residence region

\begin{tabular}{|c|c|c|c|c|c|c|c|}
\hline \multirow{2}{*}{ Characteristic } & \multicolumn{4}{|c|}{ Region } & \multicolumn{2}{|c|}{ Total } & \multirow{3}{*}{\begin{aligned} \multicolumn{1}{c}{$\boldsymbol{X}^{2}(\mathbf{p})$} \\
18.8 \\
$(0.001)^{*}\end{aligned}$} \\
\hline & \multicolumn{2}{|c|}{ Alexandria } & \multicolumn{2}{|c|}{ Others } & & & \\
\hline $\begin{array}{l}\text { Gender } \\
\text { Male } \\
\text { Female }\end{array}$ & $\begin{array}{l}\text { No. } \\
245 \\
6561\end{array}$ & $\begin{array}{r}\% \\
3.6 \\
96.4\end{array}$ & $\begin{array}{l}\text { No. } \\
12 \\
1082\end{array}$ & $\begin{array}{r}\% \\
1.1 \\
98.9\end{array}$ & $\begin{array}{l}\text { No. } \\
257 \\
7643\end{array}$ & $\begin{array}{r}\% \\
3.3 \\
96.7\end{array}$ & \\
\hline $\begin{array}{l}\text { Age (years) } \\
<30 \\
30- \\
40- \\
50- \\
60- \\
70+\end{array}$ & $\begin{array}{l}\text { No. } \\
131 \\
698 \\
1708 \\
2029 \\
1358 \\
512\end{array}$ & $\begin{array}{c}\% \\
2.0 \\
10.8 \\
26.5 \\
31.5 \\
21.1 \\
8.0\end{array}$ & $\begin{array}{r}\text { No. } \\
21 \\
166 \\
310 \\
286 \\
171 \\
68\end{array}$ & $\begin{array}{r}\% \\
2.1 \\
16.2 \\
30.3 \\
28.0 \\
16.7 \\
6.7\end{array}$ & $\begin{array}{l}\text { No. } \\
152 \\
864 \\
2018 \\
2315 \\
1529 \\
580\end{array}$ & $\begin{array}{l}\% \\
2.0 \\
11.6 \\
27.1 \\
31.0 \\
20.5 \\
7.8\end{array}$ & $\begin{array}{l}40.6 \\
(0.001)\end{array}$ \\
\hline $\begin{array}{l}\text { Range } \\
\text { Mean } \pm \text { SD }\end{array}$ & \multicolumn{2}{|c|}{$\begin{array}{c}15-90 \\
52.4 \pm 11.8 \\
\end{array}$} & \multicolumn{2}{|c|}{$\begin{array}{r}24-92 \\
50.2 \pm 11.9 \\
\end{array}$} & \multicolumn{2}{|c|}{$\begin{array}{c}15-92 \\
52.2 \pm 11.9 \\
\end{array}$} & \\
\hline $\begin{array}{l}\text { Family History } \\
\text { No } \\
\text { First degree } \\
\text { Second degree } \\
\text { others }\end{array}$ & $\begin{array}{l}\text { No. } \\
1931 \\
386 \\
165 \\
23\end{array}$ & $\begin{array}{r}\% \\
77.1 \\
15.4 \\
6.6 \\
0.9\end{array}$ & $\begin{array}{l}\text { No. } \\
278 \\
38 \\
17 \\
2\end{array}$ & $\begin{array}{c}\% \\
83.0 \\
11.3 \\
5.1 \\
0.6\end{array}$ & $\begin{array}{l}\text { No. } \\
2209 \\
424 \\
182 \\
25\end{array}$ & $\begin{array}{r}\% \\
77.8 \\
14.9 \\
6.4 \\
0.9\end{array}$ & $\begin{array}{c}5.9 \\
(0.112)\end{array}$ \\
\hline $\begin{array}{l}\text { Menstrual history } \\
\text { Pre menopausal } \\
\text { Post menopausal }\end{array}$ & $\begin{array}{l}\text { No. } \\
1535 \\
1844 \\
\end{array}$ & $\begin{array}{l}\% \\
45.4 \\
54.6 \\
\end{array}$ & $\begin{array}{l}\text { No. } \\
238 \\
235\end{array}$ & $\begin{array}{l}\% \\
50.3 \\
49.7\end{array}$ & $\begin{array}{l}\text { No. } \\
1773 \\
2079 \\
\end{array}$ & $\begin{array}{l}\% \\
46.0 \\
54.0\end{array}$ & $3.9(0.046)^{*}$ \\
\hline $\begin{array}{l}\text { Gravida } \\
\text { Nulligravida } \\
\text { Primigravida } \\
2-4 \\
5+ \\
\text { Range } \\
\text { Median }\end{array}$ & $\begin{array}{r}\text { No. } \\
2849 \\
172 \\
1929 \\
1159 \\
0 \\
\end{array}$ & \begin{tabular}{|l|}
$\%$ \\
46.6 \\
2.8 \\
31.6 \\
19.0 \\
18 \\
\end{tabular} & $\begin{array}{r}\text { No. } \\
588 \\
16 \\
264 \\
171 \\
0 \\
\end{array}$ & $\begin{array}{l}\% \\
56.6 \\
1.5 \\
25.4 \\
16.5 \\
13 \\
0\end{array}$ & $\begin{array}{r}\text { No. } \\
3437 \\
188 \\
2193 \\
1330 \\
0- \\
\end{array}$ & $\begin{array}{l}\% \\
48.1 \\
2.6 \\
30.7 \\
18.6 \\
18\end{array}$ & $\begin{array}{c}37.8 \\
(0.001)^{*}\end{array}$ \\
\hline $\begin{array}{l}\text { Parity } \\
\text { Nullipara } \\
\text { Primipara } \\
2-4 \\
5+ \\
\end{array}$ & $\begin{array}{l}\text { No. } \\
2882 \\
224 \\
2250 \\
748\end{array}$ & \begin{tabular}{l|}
$\%$ \\
47.2 \\
3.7 \\
36.9 \\
12.3 \\
\end{tabular} & $\begin{array}{r}\text { No. } \\
595 \\
17 \\
289 \\
135\end{array}$ & $\begin{array}{c}\% \\
57.4 \\
1.6 \\
27.9 \\
13.0\end{array}$ & $\begin{array}{c}\text { No. } \\
3477 \\
241 \\
2539 \\
883\end{array}$ & $\begin{array}{l}\% \\
48.7 \\
3.4 \\
35.6 \\
12.4\end{array}$ & $\begin{array}{c}50.2 \\
(0.001)\end{array}$ \\
\hline $\begin{array}{l}\text { Oral Contraceptives } \\
\text { No } \\
\text { Yes }\end{array}$ & $\begin{array}{l}\text { No. } \\
867 \\
279\end{array}$ & $\begin{array}{c}\% \\
75.7 \\
24.3\end{array}$ & $\begin{array}{l}\text { No. } \\
103 \\
47\end{array}$ & $\begin{array}{c}\% \\
68.7 \\
31.3\end{array}$ & $\begin{array}{l}\text { No. } \\
970 \\
326\end{array}$ & $\begin{array}{l}\% \\
74.8 \\
25.2\end{array}$ & $\begin{array}{c}3.4 \\
(0.064)\end{array}$ \\
\hline
\end{tabular}

$X^{2}$ : Pearson Chi Square test, * $\mathrm{P}<0.05$ (Significant)

The \pm is used to indicate the upper $(+)$ and the lower (-) confidence limits, and you can remove it, but this is the standard equation notation, and 60.2 says that the project population might be higher (+) or lower (-) by 60 cases. The predicted number of cases is shown in table (5).

\section{Discussion}

Community health can be viewed as a complex and dynamic system in which the patterns of diseases exist, persist and vary over geography and time. GIS technology uses information on geographical areas to explore why people are engaged in some high risk behaviours and some influences on cancers and cancer related behaviors. ${ }^{1-3}$

Using mapped data in cancer research is gaining in prominence, especially with the development of spatial, and geovisualisation tools. ${ }^{17}$ The application of geospatial approaches across the 
Table 3: Distribution of the collected breast cancer cases

\begin{tabular}{|l|r|}
\hline Breast cancer cases database & Number $(\%)$ \\
\hline All collected Cases: & $\mathbf{7 9 0 0}(\mathbf{1 0 0})$ \\
Faculty of Medicine cases & $\mathbf{3 4 4 6}(\mathbf{4 3 . 6 2})$ \\
$\begin{array}{l}\text { Future Hands Centre Cases } \\
\text { Medical Research Institute }\end{array}$ & $\mathbf{2 4 2 2}(\mathbf{3 0 . 6 6})$ \\
Cases & $\mathbf{2 0 3 2}(\mathbf{2 5 . 7 2 )}$ \\
$\begin{array}{l}\text { Geolocated Alexandria } \\
\text { governorate cases }\end{array}$ & $\mathbf{4 5 3 4}(\mathbf{5 7 . 3 9})$ \\
$\begin{array}{l}\text { Alexandria cases with precise } \\
\text { dates } *\end{array}$ & $\mathbf{2 0 2 5}(\mathbf{2 5 . 6 3 )}$ \\
\hline
\end{tabular}

* Precise dates were used for predicting future breast cancer cases.

cancer control continuum is closely tied to several efforts internationally. An

Table (4): Significant clusters as determined by spatial scan statistic

\begin{tabular}{|c|l|c|c|c|c|}
\hline $\begin{array}{c}\text { Cluster } \\
\text { number }\end{array}$ & \multicolumn{1}{|c|}{ District } & $\begin{array}{c}\text { Number of } \\
\text { breast cancer } \\
\text { cases }\end{array}$ & $\begin{array}{c}\text { Relative } \\
\text { Risk } \\
\mathbf{( R r )}\end{array}$ & $\begin{array}{c}\text { Likelihood } \\
\text { ratio (Lr) }\end{array}$ & P value \\
\hline 4 & Montaza & 1079 & 2.184 & 19.17 & $<0.0001$ \\
\hline 3 & $\begin{array}{l}\text { Al Attarin; Al Labban; } \\
\text { Karmuz; Muharam Bik; Al } \\
\text { Manshiyya; Bab Sharqi, Al } \\
\text { Gumruk }\end{array}$ & 531 & 1.47 & 8.27 & $<0.0001$ \\
\hline 2 & $\begin{array}{l}\text { Al Amreia; Burg Al-Arab } \\
\text { City; Al Dikhila; Burg al- } \\
\text { Arab }\end{array}$ & 1421 & 1.17 & 8.22 & $<0.0001$ \\
\hline 1 & $\begin{array}{l}\text { Sidi Gabir; Mina Al-Basal; } \\
\text { Al Raml; Kesm tani Al Raml }\end{array}$ & 1503 & 1.99 & 13.12 & $<0.0001$ \\
\hline
\end{tabular}

To accomplish these aims, a retrospective study was conducted where 3534 geolocated Alexandria governorate cancer breast cases were enrolled out of 7900 identified cases including the interpolated cases. Clustering was performed on the basis of grouping the breast cancer cases based on the distance between cases.

Regarding the Spatial and Geographic cluster analysis of the enrolled cancer breast subjects during the period from 2005-2014, the current study revealed The spatial scan statistic detected fifteen clusters, of which four were significant local clusters $(p<0.001)$. Out of those clusters, 1079 cases constituted the highest significant cluster of cases in Montaza district, through the period between 2005 and 2014, with highest prevalence and the strongest relative risk $(\mathrm{RR}=2.184, \mathrm{p}<0.001)$. example of this is the Precision Medicine Initiative in USA, which is a comprehensive effort to better understand which treatments work for which individuals and under which conditions.

The present study was conducted to portray the geographical distribution of cancer breast in Alexandria sub districts, to identify cluster areas and to demonstrate some of the socio demographic characteristics of the identified cluster areas.
The detection of local clusters in the present study can serve as a basis for prioritization of areas for future targeted and evidence based screening interventions and mass treatment.

Thereby, cancer breast prevalence does not only vary between countries, as was noted before but also on small geographic scales such as districts and subdistricts areas within one governorate in one country.

This variation of cancer breast prevalence found in the present study corresponds with findings of another spatial analysis of cancer breast in Subhojit Dey et $\mathrm{al}^{24}$, who explored urban-rural differences in breast cancer incidence over 8 years in Egypt using Gharbiah population-based cancer registry. However this study did not use GIS as a tool. They observed higher 
Table (5): Distribution of admitted and predicted cases of cancer breast (20052020)

\begin{tabular}{|l|l|l|}
\hline Year & Number of cases & $\begin{array}{c}\text { Predicted } \\
\text { number of } \\
\text { cases }\end{array}$ \\
\hline 2005 & 323 & 264 \\
2007 & 330 & 322 \\
2008 & 341 & 352 \\
2009 & 280 & 381 \\
2010 & 388 & 410 \\
2012 & 476 & 469 \\
2013 & 559 & 498 \\
$\mathbf{2 0 0 6}$ & & $\mathbf{2 9 3} *$ \\
$\mathbf{2 0 1 1}$ & & $\mathbf{4 4 0}$ \\
$\mathbf{2 0 1 4}$ & & $\mathbf{5 2 8}$ \\
$\mathbf{2 0 1 5}$ & & $\mathbf{5 5 7}$ \\
$\mathbf{2 0 1 6}$ & & $\mathbf{5 8 6}$ \\
$\mathbf{2 0 1 7}$ & & $\mathbf{6 1 6}$ \\
$\mathbf{2 0 1 8}$ & & $\mathbf{6 4 5}$ \\
$\mathbf{2 0 1 9}$ & & $\mathbf{6 7 4}$ \\
$\mathbf{2 0 2 0}$ & & $\mathbf{7 0 4}$ \\
$\mathbf{2 0 3 0}$ & & $\mathbf{1 0 0 2}$ \\
$\mathbf{2 0 4 0}$ & & $\mathbf{1 2 9 6}$ \\
$\mathbf{2 0 5 0}$ & & $\mathbf{1 5 8 9}$ \\
\hline
\end{tabular}

Bold font: predicted cases; Predicted No. of cases $=-58517+29.32 *$ year $; r^{2}=0.69$ incidence of cancer breast in urban rather than rural areas.

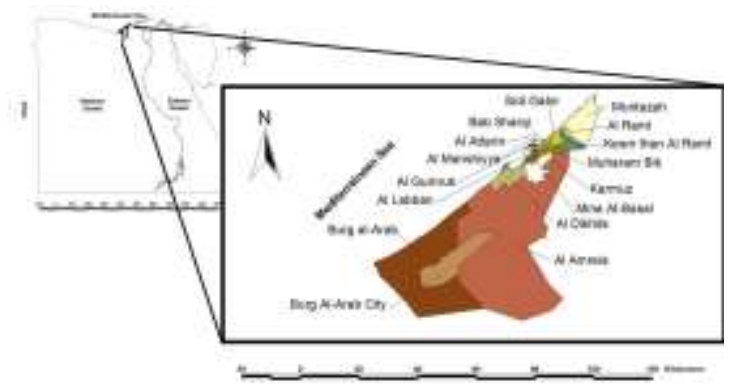

Figure 1: Location of Alexandria Governorate and its districts

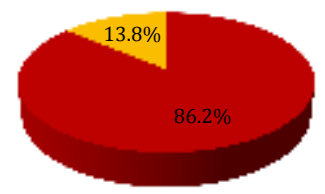

- Alexandria

Others

Figure (2): distribution of the surveyed females with breast cancer by their residence region

Other studies used spatial and aspatial statistics in their geospatial investigation into cancer. ${ }^{25-30}$

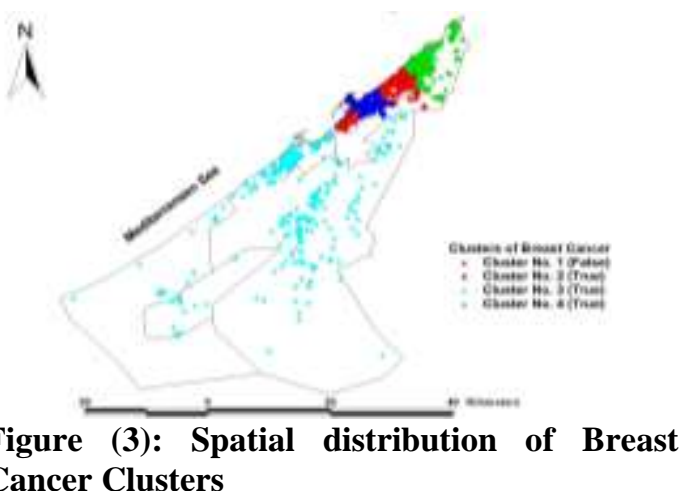

Cancer Clusters

Han $D^{27}$ in his study in 2017 aimed at continuing evaluation on the role of environmental risks on breast cancer and developed a GIS-based model of lifetime residential history and environmental exposure in breast cancer and he integrated GIS and a spatio-temporal perspective into breast cancer epidemiology. Paz et al. ${ }^{29}$ used ArcGIS software to geocode the location of the patients' homes. They also used the 'spatial join' tool of the ArcGIS 9 software, which merges geographical information from different geographic layers based on the spatial location of individual features in these layers. Meanwhile, Mandal et al. ${ }^{30}$ used Hot Spot Analysis (Getis-Ord Gi* statistic) in ArcGIS 9.3 for spatial clustering analysis of breast cancer in the United States between 2000 and 2005 .

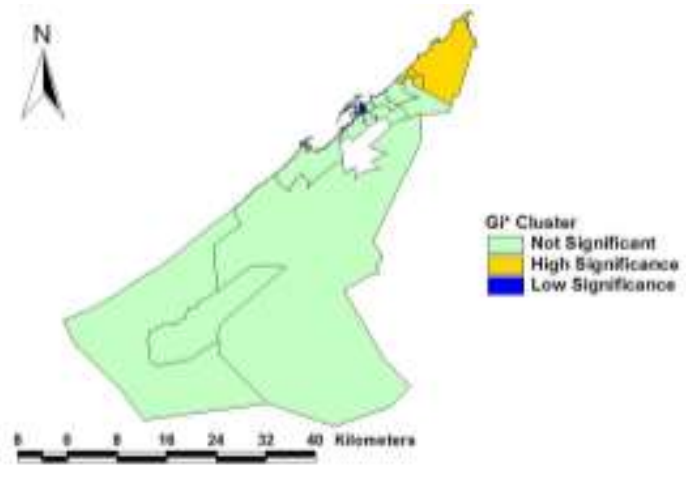

Figure (4): Gi* significant statistics

Despite the promising GIS tool for cancer control, previous studies addressed some limitations or methodological issues related to the definition of contextual environments in which people conduct their everyday 
lives. ${ }^{31-33}$ These include focusing on the residence only when most people spend one third of their time elsewhere ${ }^{31}$; failure to consider cumulative exposures over time (e.g., residential history) and changes in residential neighborhood conditions over time.

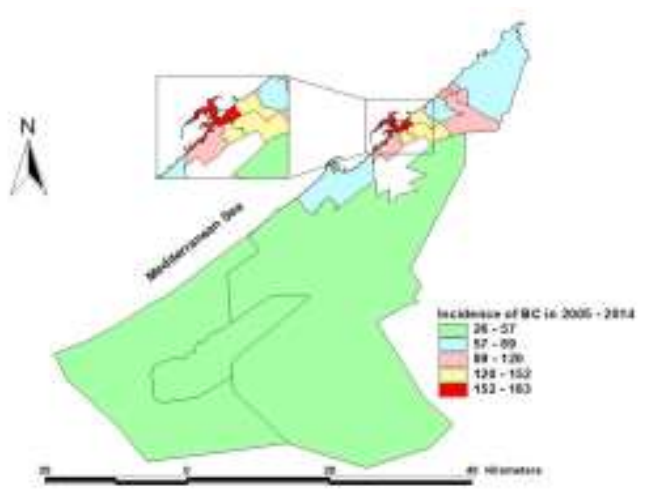

Figure (5): Breast cancer rates in Alexandria per 100000 female population n 2005-2014

Besides, In the process of Geocoding, where geographic coordinates (as latitude and longitude) are identified, the completeness and accuracy with which it is done can differ, and this can affect the findings of spatial epidemiologic analyses and lead to different types of bias in a study's outcomes. $5,16-18$

The present study recommends further studies to investigate the significant clusters to explore and explain clustering variability, environmentally and from

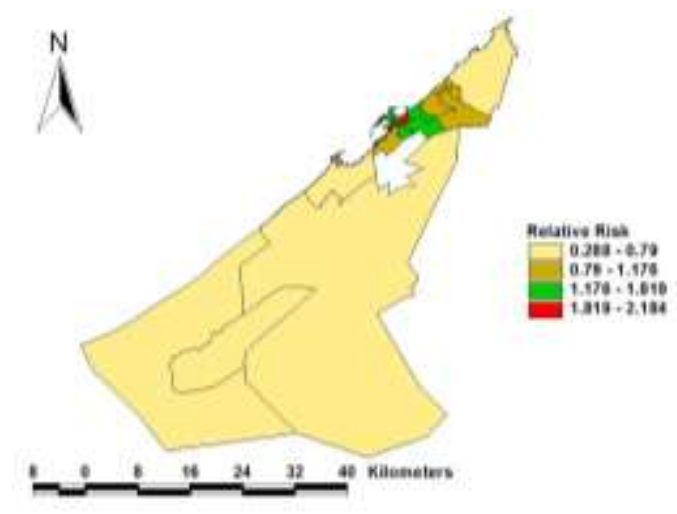

Figure (6): Relative risk of breast cancer cases distribution by district

health services aspect, and further research on geographical distributions over time, to map and analyze distribution of other cancers as cervical, lung, hepatic or colorectal.
From the prevention efforts point, the value of applying such methodology to breast cancer can help primary, secondary and tertiary prevention, in addition to surveillance necessary to show geographical shifts in distribution over time and thus plan the appropriate preventive measures as awareness campaigns or screening.

Ethical Consideration: Privacy and Confidentiality of data was ensured. All data were transferred anonymously. Addresses information were confidential through geographic masking to avoid reverse geocoding and re-identification of cases.

Acknowledgement: The study was supported financially by Alexandria Regional Centre for women's health and development.

\section{References}

1. Ricketts TC. Geographic information systems and public health. Annual Review of Public Health. 2003;24(1):1-6.

2. Lombardo JS, Buckeridge DL. Disease surveillance: a public health informatics approach: John Wiley \& Sons; 2012.

3. WHO 2006.Cancer Control: Knowledge into Action. In WHO Guide for Effective Programmes: Module 1-Planning; World Health Organization: Geneva, Switzerland.

4. Design of a location-allocation model for some health care facilities in Alexandria based on geographic information system [press release]. Alexandria University , Faculty of Medicine. Public Health 2006

5. Boulos DN, Ibrahim EM, Abdelmalik P. An eight year snapshot of geospatial cancer research (2002-2009):

clinicoepidemiological and methodological findings and trends. Med Oncol, 2011;28:1145-62.

6. Neteler M, Mitasova H. Open source GIS: a GRASS GIS approach: Springer Science \& Business Media; 2013.

7. Longley PA, Goodchild MF, Maguire DJ, Rhind DW. Geographic information science and systems: John Wiley \& Sons; 2015.

8. Benedetti R, Piersimoni F, Postiglione P. GIS: The Essentials. Sampling Spatial Units 
for Agricultural Surveys: Springer; 2015. p. 49-62.

9. Zandi S. GeoComputational methods for surface and field data interpolation: Auckland University of Technology; 2013.

10.McClendon B, Rohlf J. Network link for providing dynamic data layer in a geographic information system. Google Patents; 2011.

11. Mandel LH. Geographic information systems: tools for displaying in-library use data. Information Technology and Libraries. 2013;29(1):47-52.

12. Ibrahim AS, Khaled HM, Mikhail NN, Baraka H, Kamel H. Cancer incidence in Egypt: results of national population-based cancer registry program. J Cancer Epidem 2014;(2014):1-7.

13. Hirko KA, Soliman AA, Hablas A et al. Trends in breast cancer incidence by age and stage at diagnosis in Gharbeya., Egypt over 10 years. J Cancer Epidem, 2013;2013:1-7

14. Shaw NT. Geographical information systems and health: current state and future directions. Healthcare informatics research. 2012;18(2):88-96.

15. Wang LU. Geocoding health data: The use of geographic codes in cancer prevention and control research, and practice. In: Rushton GAM, Gittler J, Green B, PavlikdC, (eds). Boca Raton, London, New York: CRC Press; 2008. 517-8.

16. Kate H, Nicole V. GIS Application in Health: an Introduction to GIS University of Nebraska Medical Center College of Public Health 2007.

17. Clarke KC, McLafferty SL, Tempalski BJ. On epidemiology and geographic information systems: a review and discussion of future directions. Emerg Infect Dis 1996; 2(2):85-9.

18. Devasundaram JK, Rohn D, Dwyer DM, Israel E. A geographic information systems application for disease surveillance. Am J Public Health 1998; 88(9):1406-7.

19. ESRI. ArcGIS 10.2 User Manual. 2016. Environmental System Research Institute. Redlands, California, USA.

20. Information Management Services, Inc. SatScan Software User Manual 2016. http://www.satscan.org. (last visited 10/10/2016)

21. CAPMAS. Egypt Administrative

Boundaries.

https://www.humanitarianresponse.info/en/o perations/egypt/dataset/egypt-admin-level-1boundaries-admin-level-2-boundariesadmin-level-3 (Last visited 10/10/2015).

22. Google Maps. 2015. https://www.google.com.eg/maps/?hl=en (accessed 20/10/2015).

23. Hosny G, Elkaffas SM. A prediction model for the incidence patterns of female breast cancers in Alexandria, Egypt. J Egypt Public Health Assoc. 2002;77(3-4):329-345. 24. Subhojit Dey, Soliman AS, Hablas A, Seifeldin IA, Ismail $\mathrm{K}$ et al. Urban-rural differences in breast cancer incidence in Egypt (1999-2006). Breast, 2010;19 (5):41723.

25. Gorey KM, Luginaah IN, Hamm C, Fung KY, Holowaty EJ. Breast cancer care in the Canada and the United States: ecological comparisons of extremely impoverished and affluent urban neighborhoods. Health Place. 2010;16(1):156-63.

26. Hunter PR, Izsak J, Izsak J, Changes of neoplasm concentration with geographical co-ordinates. Health Place. 2003;9(4):30513.

27. Han D. Integrating GIS into breast cancer epidemiologic research. Int $\mathbf{J}$ Health Geogr. 2017;6:32.

28.

29. Pearce J, Boyle P, Flowerdew R. Predicting smoking behavior in census output areas across Scotland. Health Place. 2003;9(2):139-49.

30. Paz S, Linn S, Portnov BA, Lazimi A, Futerman B, Barchana M. Non-Hodgkin Lymphoma (NHL) linkage with residence near heavy roads - a case study from Haifa Bay, Israel. Health Place. 2009;15(2):636-41

31. Mandal R, St-Hilaire S, Kie JG, Derryberry D. Spatial trends of breast and prostate cancers in the United States between 2000 and 2005. Int J Health Geogr. 2009;8:53.

32. Hurvitz PM, Moudon AV, Kang B, Fesinmeyer MD, Saelens BE. How far from home? The locations of physical activity in an urban U.S. setting. Preventive medicine. 2014;69:181-6. doi: 10.1016/j.ypmed.2014.08.034. [PMC free article] [PubMed] [Cross Ref]

33. Wheeler DC, Wang A. Assessment of residential history generation using a publicrecord database. Int $\mathbf{J}$ Environ Res Public Health. 2015;12(9):11670-82.

\section{The Egyptian Journal of Community Medicine} 2019 
34. Krieger N, Chen JT, Waterman PD, Soobader MJ, Subramanian SV, Carson R. Geocoding and monitoring of US socioeconomic inequalities in mortality and cancer incidence: does the choice of area- based measure and geographic level matter?: the Public Health Disparities Geocoding Project. American journal of epidemiology. 2002; 156(5):471-82. 